\title{
Evodiamine sensitizes BGC-823 gastric cancer cells to radiotherapy in vitro and in vivo
}

\author{
CHENGQI HU $^{1}$, XUEXIANG GAO ${ }^{1}$, YUANYUAN HAN ${ }^{1}$, QI GUO $^{1}$, KAILIANG ZHANG ${ }^{1}$, \\ MIAOMIAO LIU ${ }^{1}$, YUGANG WANG ${ }^{2}$ and JING WANG $^{1}$ \\ ${ }^{1}$ Department of Oral Medicine, School of Stomatology, Lanzhou University, Lanzhou, Gansu 730000, P.R. China; \\ ${ }^{2}$ Department of Urology, University of Michigan School of Medicine, Ann Arbor, MI 48109, USA
}

Received May 11, 2015; Accepted March 11, 2016

DOI: $10.3892 / \mathrm{mmr} .2016 .5237$

\begin{abstract}
The present study aimed to investigate the ability of evodiamin (EVO) to sensitize BGC-823 gastric cancer cells to radiotherapy and to elucidate the underlying mechanisms. First, the sensitizing effects of EVO to radiation were demonstrated in vitro using an MTT and a clonogenic assay. Flow cytometric analysis further revealed that the inhibition of cell cycle progression of BGC-823 cells by radiation was enhanced by EVO in vitro. Furthermore, BGC-823 cell-derived xenograft models were established and animals were divided into the following four treatment groups: Control group, evodiamin group, radiotherapy group and combined therapy group. The volume and weight of the xenograft tumors were measured, from which the tumor the tumor growth curve was drawn and the inhibition rate was calculated, respectively. The results revealed that combined therapy inhibited tumor growth to a greater extent than mono treatments. The tumor inhibition rate and the level of apoptosis in the combination group (48.8\%) were significantly higher than those in the other groups $(\mathrm{P}<0.05)$. Immunohistochemistry was used to reveal that the expression of Bcl-2, phosphorylated Akt and Her-2 was significantly decreased, while Bax was increased in the xenograft tumors subjected to radiation, which was significantly enhanced by EVO. In conclusion, EVO was demonstrated to sensitize BGC-823 cells to radiation therapy and markedly inhibited xenograft tumor growth. Furthermore, downregulation of Her-2/AKT/Bcl-2 signaling was shown to be involved in this process. These results suggested that EVO may be a
\end{abstract}

Correspondence to: Miss. Jing Wang, Department of Oral Medicine, School of Stomatology, Lanzhou University, 222 Tianshui South Road, Lanzhou, Gansu 730000, P.R. China

E-mail:1zukqwj@126.com

Mr. Yugang Wang, Department of Urology, University of Michigan School of Medicine, 1301 Catherine Street, Ann Arbor, MI 48109, USA

E-mail:wangyg03@gmail.com

Key words: evodiamin, BGC-823, radiotherapy, Bcl-2, AKT, Her-2 good candidate for combined therapy with radiation in the treatment of human gastric cancer.

\section{Introduction}

Gastric cancer is the fourth most common cancer and the second leading cause of cancer-associated mortality in developed countries (1). Surgery remains the most effective treatment and accordingly, patients with resectable tumors have a better prognosis. However, most of these patients suffer a relapse at a later stage. Since early detection is difficult, gastric cancer is detected at the advanced stage in approximately two thirds of all patients, survival rates remain low (2). Surgical treatment alone is not effective in patients with local and distal recurrence, who are therefore subjected to radiotherapy (3), which is the current standard treatment for patients with a high risk of recurrence. The first radiotherapy techniques developed, however, have limitations due to destruction of surrounding normal tissue, thereby causing serious adverse reactions. To overcome this problem, radiotherapy is being increasingly combined with targeted drugs for the treatment of human cancer (4).

Evodiamine (EVO) is one of the main constituents of Tetradium genus and has been shown to have bioactive properties, including anti-tumor $(5,6)$, anti-nociceptive $(7,8)$, vasodilatative (9), stimulatory catecholamine secretion (10) as well as anti-biotic and anti-inflammatory (11) effects. Previous studies by our group proved that EVO increased the radiosensitity of Tca-8113 human oral squamous cell carcinoma cells in vitro and in vivo and inhibited cell invasion and metastasis $(12,13)$. However, the role of EVO as a sensitizer of other cancer types to radiotherapy has remained elusive. The present study assessed the efficacy of EVO combined with radiotherapy in the treatment of human gastric cancer in vitro as well as in vivo. EVO was revealed to enhance the responses of gastric cancer cells to radiotherapy, suggesting that it may be applied in the clinic to improve the efficacy of gastric cancer treatment.

\section{Materials and methods}

Cell culture. The BGC-823 human gastric carcinoma cell line was purchased from Shanghai Institutes for Biological Sciences, Chinese Academy of Sciences (Shanghai, China) 
and were cultured in RPMI 1640 medium (Gibco; Thermo Fisher Scientific, Inc., Waltham, MA, USA), supplemented with $10 \%$ fetal bovine serum (Hangzhou Sijiqing Biological Engineering Materials Co., Ltd., Zhejiang, China), penicillin (100 U/ml; Gibco; Thermo Fisher Scientific, Inc.) and streptomycin $\left(100 \mathrm{mg} / \mathrm{ml}\right.$; Thermo Fisher Scientific, Inc.) at $37^{\circ} \mathrm{C}$ in a humidified atmosphere containing $5 \% \mathrm{CO}_{2}$. Cells were and passaged upon reaching 70-80\% confluence.

Reagents and instruments. EVO was purchased from Phytomarker Ltd. (Tianjin, China) and dissolved in Tween 80 (0.5\%; Sigma-Aldrich, St. Louis, MO, USA) and then diluted with $\mathrm{NaCl}$ solution to a final concentration of $1 \mathrm{mg} / \mathrm{ml}$. Primary antibodies against Bcl-2 (mouse monoclonal; 1:200; cat. no. ZM-0010) and Bax (mouse monoclonal; 1:150; cat. no. ZA-0611) were obtained from Zhongshan Golden Bridge Biotechnology Co., Ltd. (Beijing, China). Primary monoclonal antibodies against Her-2 (rabbit monoclonal; 1:200; cat. no. 2242) and phosphorylated (p-)Akt (rabbit IgG; 1:200; cat. no. 4060) were purchased from Cell Signaling Technology, Inc. (Beverly, MA, USA). An Elekta linear accelerator (Stockholm, Sweden) was applied for radiotherapy. 3-(4,5-dimethylthiazol-2-yl)-2,5-diphenyltetrazolium bromide (MTT), dimethyl sulfoxide, hematoxylin, eosin and phosphate-buffered saline (PBS) were purchased from Boster Bioengineering Co., Ltd. (Wuhan, China)

Cell proliferation assay. Cells (1,000 cells/ml) were seeded in a 96-well plate and subjected to the indicated treatments. After 24,48 or $72 \mathrm{~h}$ of treatment with $\operatorname{EVO}(1,4$ or $16 \mu \mathrm{M})$ and X-radiation $(2,4,6$ or $8 \mathrm{~Gy})$, cells were stained with MTT $(10 \mu \mathrm{l})$ and incubated at $37^{\circ} \mathrm{C}$ for $4 \mathrm{~h}$. Cells were then lysed in $100 \mu \mathrm{l}$ dimethyl sulfoxide and the optical density value was measured at $570 \mathrm{~nm}$ using a 96-well plate reader.

Clonogenic cell survival assay. Cells were seeded into 6-well plates and after $24 \mathrm{~h}$ incubation, were incubated with $4 \mu \mathrm{mol} / 1$ EVO for a further $24 \mathrm{~h}$. The cells were then irradiated with various doses $(2,4,6$ or $8 \mathrm{~Gy})$ of X-radiation at a dose rate of $2 \mathrm{~Gy} / \mathrm{min}$. The cells were allowed to form colonies in drug-free medium over 10 days for the determination of clonogenic cell survival. The cells were then stained with $0.05 \%$ crystal violet in $100 \%$ methanol, and colonies comprising $>50$ cells were counted. Clonogenic survival curves were plotted using the 'Multitarget single hit' model.

Cell cycle distribution. Cells $\left(2 \times 10^{6}\right)$ were seeded in $100-\mathrm{mm}$ plates and subjected to various treatments [control group (C), untreated; EVO group (E), treated with ( $4 \mu \mathrm{mol} / \mathrm{l}) \mathrm{EVO}$; radiotherapy group (R), treated with 2, 4, 6 or 8 Gy of X-radiation; and combined therapy group (E+R)]. After $48 \mathrm{~h}$, the cells were washed with PBS and then fixed in $70 \%$ ethanol at $-20^{\circ} \mathrm{C}$ overnight. Cells were then washed with PBS and re-suspended in propidium iodide solution $(200 \mu \mathrm{l})$, incubated in the dark for $30 \mathrm{~min}$ and then analyzed by flow cytometry (Beckman Coulter, Inc., Brea, CA, USA). The experiment was performed in triplicate.

In vivo tumor xenograft model. Sixteen male BALB/c mice (3-4 weeks old; weighing 15-18 g) raised under specific pathogen-free conditions were purchased from Vital River Laboratory Animal Technology Co. Ltd (Beijing, China). The present study was approved by the Medical Ethics Committee of Lanzhou University (Lanzhou, China). The feeding room was maintained at a constant temperature of $26-28^{\circ} \mathrm{C}$ with normal ventilation and a $12 \mathrm{~h}$ light/dark cycles (relative humidity, $50 \pm 5 \%$ ). The mice had unlimited access to a standard mouse chow diet and water. To establish the gastric carcinoma xenografts, $10^{6}$ BGC-823 cells were suspended in $100 \mu \mathrm{l}$ PBS and then subcutaneously inoculated into the left flank of each mouse. When the tumor size had reached a mean diameter of $\sim 7 \mathrm{~mm}$ after two weeks, the mice were randomly divided into four groups. The control group and the radiotherapy group was treated with placebo $(0.5 \%$ Tween 80 and $0.9 \%$ sodium chloride via oral gavage) for five consecutive days. The EVO group and the combined group received EVO orally $(10 \mathrm{mg} / \mathrm{kg}$ daily via oral gavage) for five days and then underwent mock irradiation. The tumors of the radiotherapy group were exposed to radiation at a dosage totaling $5 \mathrm{~Gy}(2 \mathrm{~Gy} / \mathrm{min})$ at $2 \mathrm{~h}$ after the final placebo treatment. The mice of the combined treatment group were treated with irradiation (5 Gy) after EVO treatment for five days. Mice were then maintained under specific pathogen-free conditions for 24 days. The volume of the sub-cutaneous tumors was measured every two days using a Vernier caliper and tumor volumes were calculated using the formula $\left(\mathrm{LxW}^{2}\right) / 2$. At the end of the experiments, all of the mice were sacrificed by cervical dislocation. Tumors were recovered and weighed, and the tumor growth inhibition rate was caculated using the following formula (14): Tumor inhibition rate $(\%)=(1$-average tumor weight in treated group/average tumor weight in control) x $100 \%$.

Morphological changes. The tumors were fixed in $10 \%$ formalin for $24 \mathrm{~h}$ at room temperature, dehydrated and then embedded in paraffin. Sections $(4 \mu \mathrm{m})$ were prepared, stained with hematoxylin and eosin and observed by light microscopy (Olympus, Tokyo, Japan). Furthermore, morphological changes of BGC-823 xenografts characteristic of apoptosis were assessed using transmission electron microscopy (TEM; Philips, Eindhoven, The Netherlands). Tumors were cut into 1x1x1-mm specimens. Subsequently, the samples were fixed in $4 \%$ glutaraldehyde overnight at $4^{\circ} \mathrm{C}$ using $0.1 \mathrm{~mol} / 1$ sodium cacodylate buffer and incubated in $1 \%$ osmium tetroxide $\left(\mathrm{OsO}_{4}\right)$ at room temperature for $1 \mathrm{~h}$. Fixed samples were washed and dehydrated using a graded ethanol series followed by $100 \%$ acetone. Tissues were then embedded in epoxy resin and ultrathin sections $(70 \mathrm{~nm})$ were prepared, which were observed by TEM.

Immunohistochemical detection of Her-2, p-Akt, Bcl-2 and Bax. Tissue sections $(4 \mu \mathrm{m})$ were de-paraffinized in xylene, hydrated and treated with $0.3 \% \mathrm{H}_{2} \mathrm{O}_{2}$ for $10 \mathrm{~min}$. Antigen retrieval was performed by standard microwave heating $\left(92-98^{\circ} \mathrm{C}\right)$ for $10 \mathrm{~min}$ in citrate buffer $(\mathrm{pH} \mathrm{6.0)}$. Slides were then probed with primary antibodies against Her-2, p-Akt, Bcl-2 and Bax overnight at $4^{\circ} \mathrm{C}$. Subsequently, slides were incubated with specific secondary antibodies (cat. no. PV-6000-D; Zhong Shan Golden Bridge Co., Ltd., Beijing, China) at $37^{\circ} \mathrm{C}$ for $1 \mathrm{~h}$. Diaminobenzidine was used for color development according to manufacturer's instructions. The proportion and 

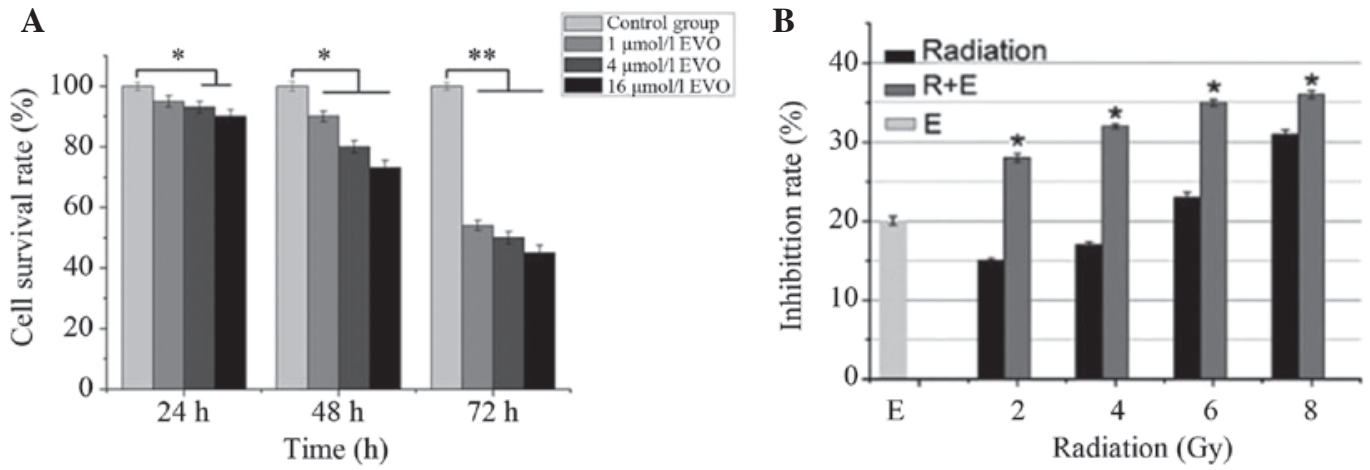

Figure 1. (A) Inhibition rate of BGC-823 cells at various concentrations and incubation times by MTT assay. (B) BGC-823 cell survival rates after radiation, $\mathrm{R}+\mathrm{E}$ or E treatments. Groups: E, EVO alone $(4 \mu \mathrm{M})$; R, radiation alone; R+E, combination treatment. Values are expressed as the mean \pm standard deviation. ${ }^{*} \mathrm{P}<0.05,{ }^{* *} \mathrm{P}<0.01$ compared with Radiation or control groups. EVO, evodiamine.
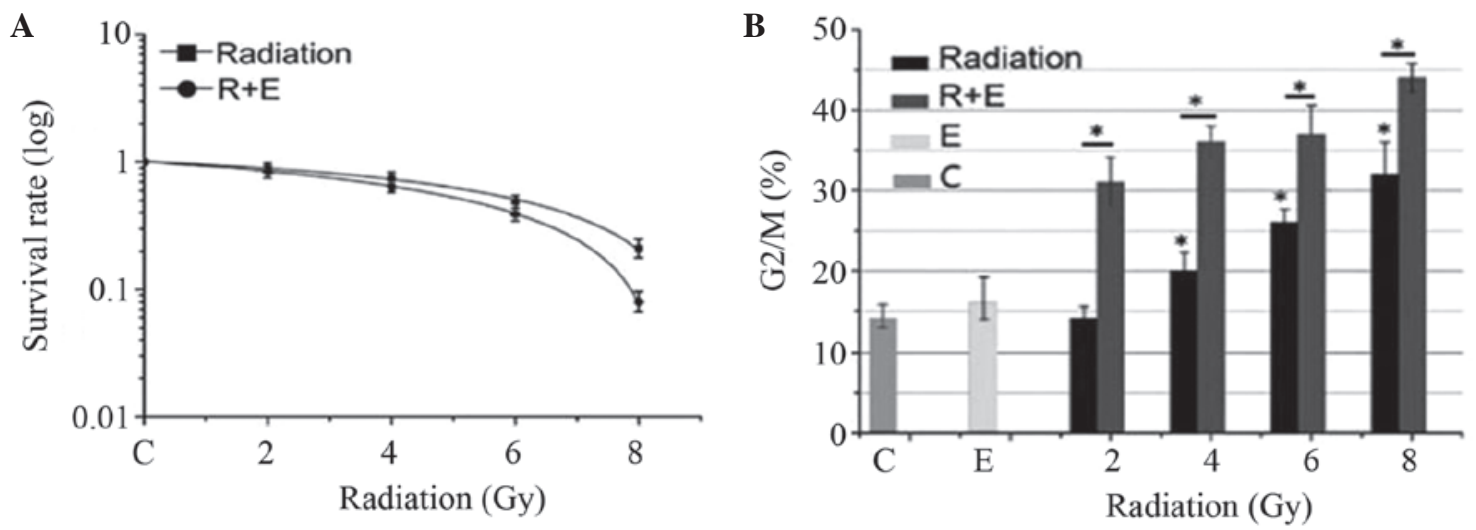

Figure 2. (A) Dose-survival curves of BGC-823 cells in the multi target single hit model. (B) Percentages of cells from different experimental groups in $\mathrm{G} 2 / \mathrm{M}$ phase of the cell cycle. Groups: C, control; E, EVO alone $(4 \mu \mathrm{M})$; R, radiation alone; R+E, combination treatment. Values are expressed as the mean \pm standard deviation. ${ }^{*} \mathrm{P}<0.05$ compared with Radiation or control groups. EVO, evodiamine.

distribution of immunoreactive cells was assessed using an optical microscope (Olympus). Semi-quantitative analysis was performed using Image J v.1.45 software (National Institutes of Health, Bethesda, MD, USA). Negative controls were obtained by excluding the primary antibody.

Statistical analysis. All analyses were performed using the SPSS 17.0 statistical software (SPSS, Inc., Chicago, IL, USA). Values are expressed as the mean \pm standard deviation. The data were subsequently analyzed using Student's t-test when only two groups were present, or assessed by one-way analysis of variance when $>2$ groups were compared. $\mathrm{P}<0.05$ was considered to indicate a statistically significant difference.

\section{Results}

$E V O$ reduces the viability of $B G C-823$ cells and enhances the efficacy of radiation in vitro. As shown in Fig. 1A, EVO time-dependently reduced the number of viabile BGC-823 cells. From the inhibition curves, the $\mathrm{IC}_{20}$ value of $\mathrm{EVO}$ was determined to be $4 \mu \mathrm{mol} / \mathrm{l}$ for the $48 \mathrm{~h}$ time-point, which was then used for combined treatment with radiation. Compared with radiation or EVO treatment alone, combined treatment demonstrated a significantly higher inhibitory effect on BGC-823 cells $(\mathrm{P}<0.05$; Fig. $1 \mathrm{~B})$ and that low-dose combination therapy is superior to the high-dose group.
EVO enhances the inhibitory effects of radiation on the clonogenic survival and cell cycle progression of BGC823 cells. As shown in Fig. 2, EVO significantly enhanced the radiosensitivity of BGC823 cells in terms of reducing clonogenic cell survival. The clonogenic survival curves (Fig. 2A) were plotted using the 'Multitarget single hit' model. The radiobiological parameters (D0=3.9 Gy, Dq=0.8 Gy, SF2=0.5) of the combination group were lower than those in the radiation only group (D0=5.0 Gy, Dq=1.2 Gy, SF2=0.8) $(\mathrm{P}<0.05)$, which indicated that combination therapy enhanced the radiosensitivity of BGC823 cells.

The effects of EVO and radiation on the cell cycle distribution of BGC823 cells were also assessed. The ability of radiation to dose-dependently induce $\mathrm{G} 2 / \mathrm{M}$ phase arrest in BGC823 cells was significantly enhanced by EVO $(\mathrm{P}<0.05)$ (Fig. 2B). Therefore, it was indicated that EVO enhanced the effect of radiation in BGC823 cells (15).

Pre-treatment with EVO sensitizes BGC-823 cell-derived xenograft tumors to radiation. To evaluate the enhanced efficacy of combined EVO and radiotherapy treatment in vivo, a murine xenograft model of human gastric carcinoma was used. Model animals were treated with EVO or placebo, followed by optional radiation therapy. According to the tumor growth curves (Fig. 3A), combined therapy with EVO and radiation showed an enhanced inhibitory effect on the 


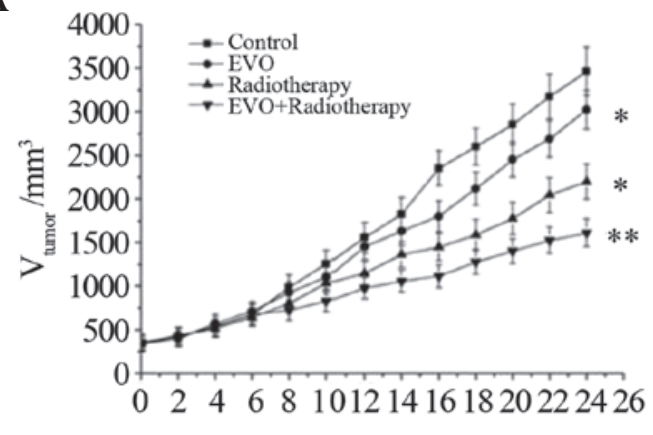

$\mathrm{t} / \mathrm{d}$

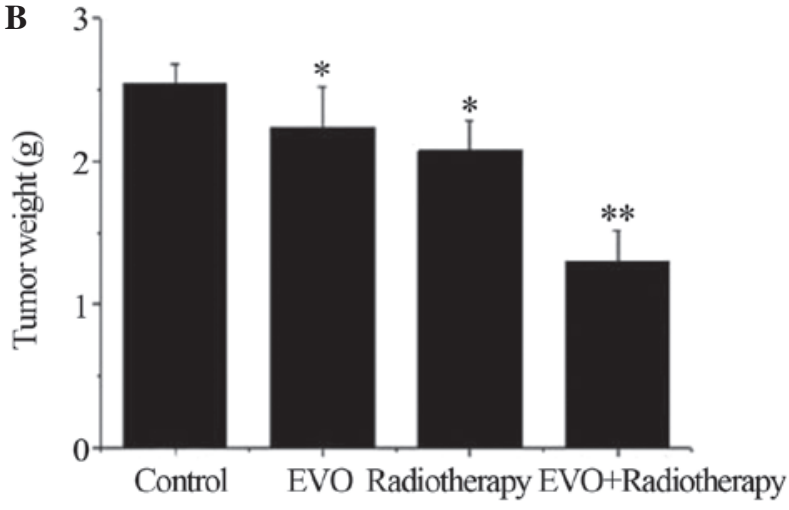

Figure 3. Inhibitory effects of EVO in combination with radiotherapy on the growth of xenograft tumors derived from BGC-823 cells in nude mice. (A) Growth curves of xenograft tumors in four groups of nude mice treated for 24 days. (B) Tumor volumes in each group. Inhibition rates: EVO, $12.1 \pm 2.8 \%$; Radiotherapy, $17.1 \pm 2.4 \%$; EVO+radiotherapy, $48.8 \pm 2.6 \%$. Values are expressed as the mean \pm standard deviation. ${ }^{*} \mathrm{P}<0.05,{ }^{* *} \mathrm{P}<0.01$ compared with control group. EVO, evodiamine; V, volume.
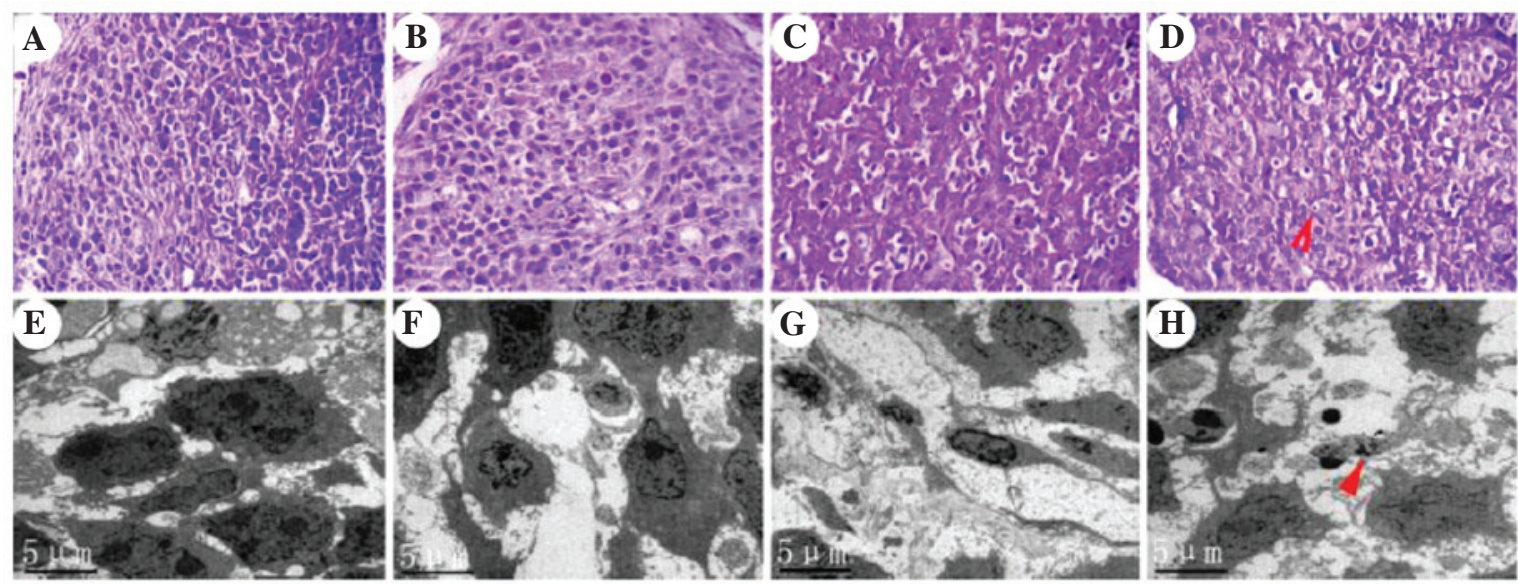

Figure 4. (A-D) Histopathological changes in xenograft tumors (hematoxylin and eosin staining; magnification, $\mathrm{x} 400$; arrow). (A) Control group, (B) EVO group, (C) Radiotherapy group, (D) EVO+radiotherapy group. (E-H) Transmission electron microscopy images revealing apoptosis of BGC-823 xenograft tumors in nude mice treated with EVO or/and radiotherapy. (E) Control group (F) EVO group, (G) Radiotherapy group (H) EVO+ radiotherapy (arrow) group. EVO, evodiamine.

tumor volume compared with that of all other treatments over 24 days $(\mathrm{P}<0.05)$. Furthermore, the tumor weight at the end of the experiment was significantly lower in the combination treatment group compared to that in the other groups, with an inhibition rate of $48.8 \pm 2.6 \%$ compared to $12.1 \pm 2.8$ and $17.1 \pm 2.4 \%$ in the EVO and radiotherapy group, respectively.

Morphological changes in xenograft tumors. Microscopic observation of histological slides of the tumors indicated that in the control group, the cells showed dense, large and deeply stained nuclei with minimal cytoplasm, and the tissue structure was in order (Fig. 4A). In the EVO group, the nuclei were distorted and shrunk, while chromatin was partly dissolved and had migrated to the cell edges (Fig. 4B). Pathological karyokinesis was markedly reduced. Cell mitosis was decreased compared with the control group. In the radiotherapy group, various degrees of cell shrinkage were present and most cells appeared necrotic (Fig. 4C). In the combination group, a large number of BGC-823 cells appeared necrotic, and the tumor volume was reduced and atrophic (Fig. 4D; arrow). Numerous
BGC823 cells showed obvious chromatin condensation, nuclear condensation, and the cellular structure was dissolved. Typical radiation-induced changes in the microstructure of BGC-823 cells were assessed by TEM. In the control group, cell structure was clear with prominent nucleoli (Fig. 4E). No significant apoptosis was observed. In the EVO group, certain cells presented a morphology characteristic of apoptosis, such as accumulation of chromatin on the cell edges (Fig. 4F). In the radiotherapy group, a number of cells showed chromatic agglutination and protoplasm concentration, and had formed apoptotic bodies (Fig. 4G), a typical phenomenon observed in cells undergoing radiation-induced apoptosis. Combination treatment was found to strongly promote apoptosis (Fig. $4 \mathrm{H}$; arrow). The number of cells was markedly decreased. Nuclear condensation, chromatin fragmentation and cell fragmentation into apoptotic bodies were frequently observed.

EVO combined with radiotherapy reduces the levels of Her-2, p-Akt and Bcl-2 and increases the expression of Bax in $B G C-823$ cells. The effects of the various treatments on the levels of certain proteins were assessed by immunohistochem- 

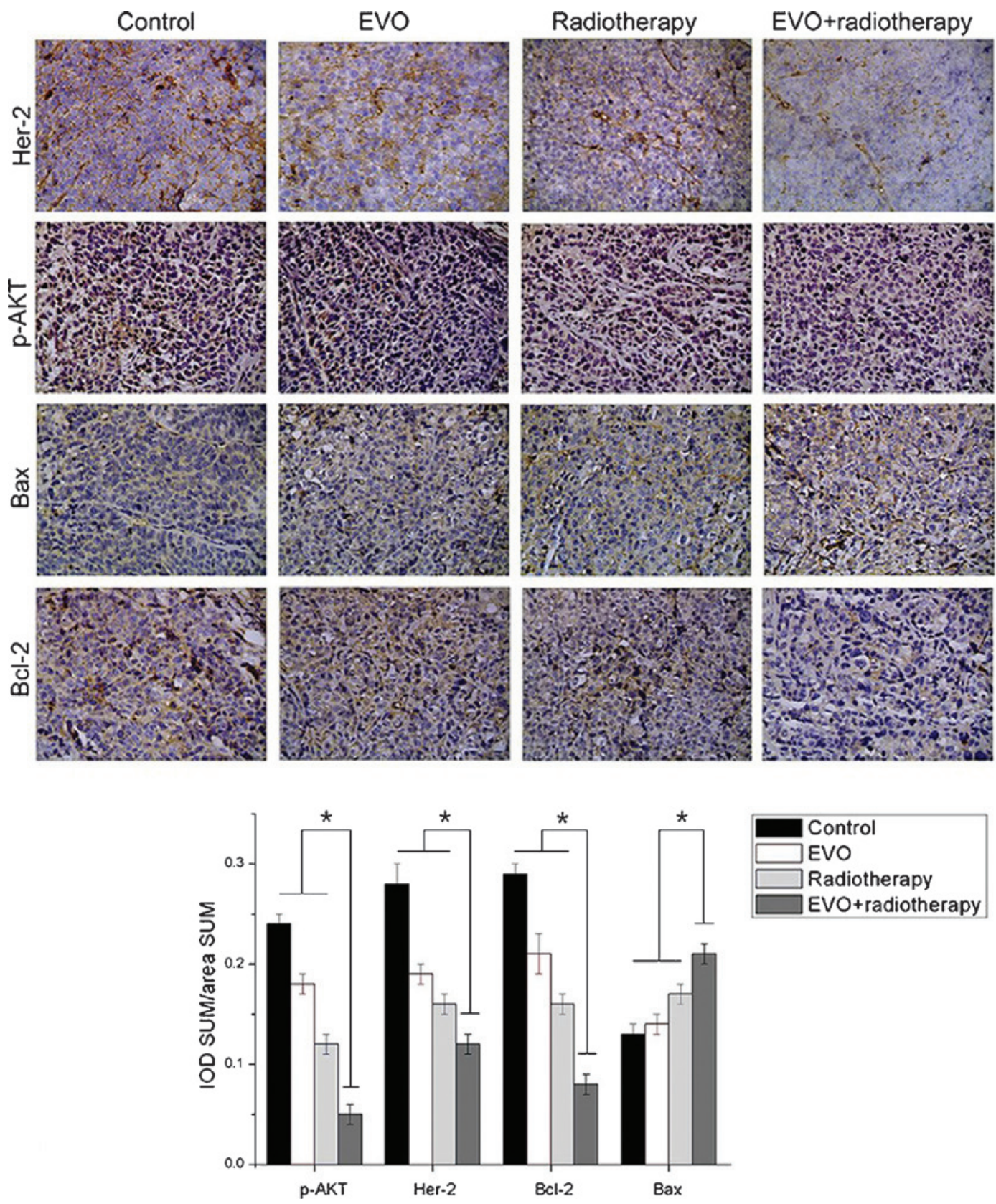

Figure 5. Expression of Her-2, p-Akt, Bcl-2 and Bax in xenograft tumors derived from BGC-823 cells as detected by immunohistochemistry (magnification, x200). Positivity for Her-2 was indicated by brown granules located on the cell membrane. p-Akt was present in the cytoplasm and the nuclei, while Bcl-2 and Bax were located in the cytoplasm. Values are expressed as the mean \pm standard deviation. ${ }^{*} \mathrm{P}<0.05$ for EVO+radiotherapy group vs. all other groups. EVO, evodiamine; p-Akt, phosphorylated Akt; Bcl-2, B-cell lymphoma 2; Bax, Bcl-2-associated X protein; IOD, integrated optical density; SUM area, the total area of positive cells.

istry followed by optical density analysis (Fig. 5). Positivity for Her-2 was indicated by brown granules located on the cell membrane. The expression levels of Her-2 in the combination group were significantly descreased compared with those in the mono treatment groups $(\mathrm{P}<0.05)$. p-Akt (activated Akt) can be found in the cytoplasm and the nuclei. The levels of p-Akt were significantly decreased in the combination group compared with those in the mono treatment groups $(\mathrm{P}<0.05)$. Positive staining for Bcl-2 and Bax was mainly located in the cytoplasm. The expression levels of Bax in the combination group were significantly higher, while those of $\mathrm{Bcl}-2$ were significantly lower than those in the mono treatment groups ( $\mathrm{P}<0.05$ for both).

\section{Discussion}

Radiotherapy serves an important role in treatment of gastric cancer at the advanced stage. In localized advanced tumors, radiotherapy has been combined with systemic agents, including chemotherapeutic drugs and radiosensitizers, to improve patient survival and outcome of the treatment (16-18). However, most radiosensitizers currently used in the clinic have toxic side effects (19). Therefore, large research efforts have been made to discover radiosensitizers with low toxicity and high efficiency. EVO is a compound extracted from the Tetradium genus of plants and has shown efficacy against various tumor types, including liver cancer (20), breast 
cancer (21) and prostate cancer (22). However, the use of EVO as a radiosensitizer has been rarely reported. Previous studies by our group indicated that EVO has radiosensitizing effects on Tca-8113 cells in vitro and in vivo $(12,13)$. Based on these findings, the present study investigated the efficacy of EVO in combination with radiotherapy in the treatment of gastric carcinoma. In vitro viability and clonogenic assays indicated that combination treatment had greater inhibitory effects on the BGC-823 gastric cancer cell line compared with mono treatments. Furthermore, flow cytometric cell cycle distribution analysis revealed that radiation dose-dependently induced cell cycle arrest in G2/M phase, which was aggravated by EVO.

The present study further demonstrated that EVO in combination with radiotherapy resulted in significantly enhanced tumor growth inhibition compared with that in the other groups in vivo. Cell morphological observation using TEM revealed that in the combination group, DNA condensation, chromatic agglutination, which are characteristics of radiation-induced apoptosis, were present. Furthermore, histological analysis revealed the presence of necrotic cells. Apoptosis induced by combined treatment with EVO and radiation is therefore a mechanism responsible for the enhanced anti-tumor effects on human gastric carcinoma. The combination group increased the inhibition of the $\mathrm{G} 2 / \mathrm{M}$ phase. It reduced the capacity of the cells for self repair following radiation damage. EVO may have enhanced the radiation-induced decreases of cell survival by reducing the capacity of the cells for self-repair following radiation damage.

The present study further hypothesized that apoptosis induced by the combination treatment was mediated through Her-2 as well as deactivation of AKT and downregulation of Bcl-2 (23). Immunohistochemical analysis revealed that treatment with $\mathrm{EVO}$ or radiation led to the downregulation of Bcl-2 and upregulation of Bax in BGC-823 cells, which is indicative of apoptosis $(24,25)$. As the combination of EVO and radiotherapy significantly increased the Bax/Bcl-2 ratio in BGC823 cells compared with mono treatment, is was further evidenced that EVO enhanced the efficacy of radiotherapy.

Her-2 is a prognostic indicator of breast cancer and expression in gastric carcinoma. It also has a significant association with the prognosis of gastric cancer, and more and more individuals are researching Her-2 in gastric cancer. The proto-oncogene Her-2 has been demonstrated to be expressed in gastric cancer tissues (26). It can enhance kinase activity, cell proliferation and cell transformation. The two signaling transduction pathways activated by Her-2 are the mitogen-activated protein kinase and the phosphoinositide-3 kinase (PI3K)/AKT pathways. Numerous studies suggested that Her-2 also modulates cell survival through activation of the PI3K/AKT pathway $(27,28)$. PI3K catalyzes the phosphorylation of phosphatidyl inositol, which concomitantly activates downstream targets, including AKT (29). The PI3K/AKT pathway is considered to be a survival pathway and can protect cells from various stresses. AKT activation promotes cell survival by modulating its downstream elements, such as Bcl-2-associated death promoter (BAD) $(30,31)$, which stimulates the expression of $\mathrm{Bcl}-2$ which exerts its anti-apoptotic effects (32-34). The Bax/Bcl-2 ratio as a molecular switch keeps a balance between proliferation and apoptosis. Therefore, the decreased expression of Her-2 may have contributed to the increase in the Bax/Bcl-2 ratio observed in present study, which subsequently caused apoptosis.

In conclusion, the present study suggested that EVO is able to sensitize gastric cancer cells to radiotherapy. It is likely that DNA damage-associated signaling may have triggered apoptosis, and that EVO may have facilitated this process. Therefore, that this requires further investigation in the future. Combined application of EVO and radiotherapy may therefore represent a suitable regimen with enhanced efficacy for the treatment of gastric cancer.

\section{Acknowledgements}

The present study was supported by grants from the National Natural Science Foundation of China (no. 81372893) and the Natural Science Foundation of Gansu Province (no. 1208RJZA193).

\section{References}

1. Siegel R, Naishadham D and Jemal A: Cancer statistics, 2013. Ca-Cancer J Clin 63: 11-30, 2013.

2. Ohtsu A, Shah MA, Van Cutsem E, Rha SY, Sawaki A, Park SR, Lim HY, Yamada Y, Wu J, Langer B, et al: Bevacizumab in combination with chemotherapy as first-line therapy in advanced gastric cancer: A randomized, double-blind, placebo-controlled phase III study. J Clin Oncol 29: 3968-3976, 2011.

3. Maier-Hauff K, Ulrich F, Nestler D, Niehoff H, Wust P, Thiesen B, Orawa H, Budach V and Jordan A: Efficacy and safety of intratumoral thermotherapy using magnetic iron-oxide nanoparticles combined with external beam radiotherapy on patients with recurrent glioblastoma multiforme. J Neurooncol 103: 317-324, 2011.

4. Begg AC, Stewart FA and Vens C: Strategies to improve radiotherapy with targeted drugs. Nat Rev Cancer 11: 239-253, 2011.

5. Li-Weber M: Targeting apoptosis pathways in cancer by Chinese medicine. Cancer Lett 332: 304-312, 2013.

6. Shu L, Cheung KL, Khor TO, Chen C and Kong AN: Phytochemicals: Cancer chemoprevention and suppression of tumor onset and metastasis. Cancer Metast Rev 29: 483-502, 2010.

7. Yuan SM, Gao K, Wang DM, Quan XZ, Liu JN, Ma CM, Qin C and Zhang LF: Evodiamine improves congnitive abilities in SAMP8 and APP(swe)/PS1 $(\triangle E$ E $)$ transgenic mouse models of Alzheimer's disease. Acta Pharmacol Sin 32: 295-302, 2011.

8. Yu H, Jin $\mathrm{H}$, Gong W, Wang $\mathrm{Z}$ and Liang $\mathrm{H}$ : Pharmacological actions of multi-target-directed evodiamine. Molecules 18: 1826-1843, 2013.

9. Xia YY, Xu HY, Cai YY, Si DY and Liu CX: Simultaneous determination of evodiamine and evodine in Beagle dog plasma using liquid chromatography tandem mass spectrometry. J Asian Nat Prod Res 15: 235-243, 2013.

10. Schwarz NA, Spillane M,La Bounty P, Grandjean PW,Leutholtz B and Willoughby DS: Capsaicin and evodiamine ingestion does not augment energy expenditure and fat oxidation at rest or after moderately-intense exercise. Nutr Res 33: 1034-1042, 2013.

11. Liao JF, Chiou WF, Shen YC, Wang GJ and Chen CF: Anti-inflammatory and anti-infectious effects of Evodia rutaecarpa (Wuzhuyu) and its major bioactive components. Chin Med 6: 6, 2011.

12. Han YY: The Radio Sensitizing Effects of EVO on Human Gastric Cancer Cells. Lanzhou University 2014 (In Chinese).

13. Li J, Zhang KL, Hu CQ, et al: Inhibitory effect of evodiamine combined with radiotherapy on the growth of xenografts of human tongue squamous-cell carcinoma Tca-8113 cells in nude mice. Tumor 2: 108-112, 2014 (In Chinese).

14. Ueno S, Yamazaki R, Ikeda T, Yaegashi T and Matsuzaki T: Antitumor effect of a novel phenanthroindolizidine alkaloid derivative through inhibition of protein synthesis. Anticancer Res 34: 3391-3397, 2014.

15. Sun H, Hou H, Lu P, et al: Isocorydine inhibits cell proliferation in hepatocellular carcinoma cell lines by inducing G2/M cell cycle arrest and apoptosis. PloS one , 7: e36808, 2012. 
16. Lawrence YR, Vikram B, Dignam JJ, Chakravarti A, Machtay M, Freidlin B, Takebe N, Curran WJ Jr, Bentzen SM, Okunieff P, et al: NCI-RTOG translational program strategic guidelines for the early-stage development of radiosensitizers. J Natl Cancer Inst 105: 11-24, 2013.

17. Ma S, Jiao B, Liu X, Yi H, Kong D, Gao L, Zhao G, Yang Y and Liu X: Approach to radiation therapy in hepatocellular carcinoma. Cancer Treat Rev 36: 157-163, 2010.

18. Morris ZS and Harari PM: Interaction of radiation therapy with molecular targeted agents. J Clin Onocl 32: 2886-2893, 2014.

19. Waseem M and Parvez S: Mitochondrial dysfunction mediated cisplatin induced toxicity: Modulatory role of curcumin. Food Chem Toxicol 53: 334-342, 2013

20. Yang J, Cai X, Lu W, Hu C, Xu X, Yu Q and Cao P: Evodiamine inhibits STAT3 signaling by inducing phosphatase shatterproof 1 in hepatocellular carcinoma cells. Cancer Lett 328: 243-251, 2013.

21. Wang KL, Hsia SM, Yeh JY, Cheng SC, Wang PS and Wang SW: Anti-proliferative effects of evodiamine on human breast cancer cells. PLoS One 8: e67297, 2013.

22. Kan SF, Huang WJ, Lin LC and Wang PS: Inhibitory effects of evodiamine on the growth of human prostate cancer cell line LNCaP. Int J Cancer 110: 641-651, 2004.

23. Sukawa Y, Yamamoto H, Nosho K, et al: HER2 expression and PI3K-Akt pathway alterations in gastric cancer. Digestion 89: $12-17,2014$.

24. Shi L, Chen J, Yang J,Pan T, Zhang S and Wang Z: MiR-21 protected human glioblastoma U87MG cells from chemotherapeutic drug temozolomide induced apoptosis by decreasing Bax/Bcl-2 ratio and caspase-3 activity. Brain Res 1352: 255-264, 2010.

25. Schwartzberg LS, Franco SX, Florance A, O'Rourke L, Maltzman J and Johnston S: Lapatinib plus letrozole as first-line therapy for HER-2+ hormone receptor-positive metastatic breast cancer. Oncologist 15: 122-129, 2010.

26. Gravalos C and Jimeno A. HER2 in gastric cancer: a new prognostic factor and a novel therapeutic target. Ann Oncol 19: 1523-1529, 2008.
27. Dave B, Migliaccio I, Gutierrez MC, Wu MF, Chamness GC, Wong H, Narasanna A, Chakrabarty A, Hilsenbeck SG, Huang J, et al: Loss of phosphatase and tensin homolog or phosphoinositol-3 kinase activation and response to trastuzumab or lapatinib in human epidermal growth factor receptor 2-overexpressing locally advanced breast cancers. J Clin Oncol 29: 166-173, 2011.

28. Bacus SS, Altomare DA, Lyass L, Spohn B, Bartholomeusz G, Yan DH and Hung MC. AKT2 is frequently upregulated in HER-2/neu-positive breast cancers and may contribute to tumor aggressiveness by enhancing cell survival. Oncogene 21: 35323540, 2002.

29. Wong KK, Engelman JA and Cantley LC: Targeting the PI3K signaling pathway in cancer. Curr Opin Genet Dev 20: 87-90, 2010.

30. Chen KC, Hsieh CL, Peng CC and Peng RY: Exercise rescued chronic kidney disease by attenuating cardiac hypertrophy through the cardiotrophin-1 - LIFR/gp 130 - JAK/STAT3 pathway. Eur J Prev Cardiol 21: 507-520, 2014.

31. Ridnour LA, Barasch KM, Windhausen AN, Dorsey TH, Lizardo MM, Yfantis HG, Lee DH, Switzer CH, Cheng RY, Heinecke JL, et al: Nitric oxide synthase and breast cancer: Role of TIMP-1 in NO-mediated Akt activation. PLoS One 7: e44081, 2012.

32. Zeng KW, Wang XM, Ko H, Kwon HC, Cha JW and Yang HO: Hyperoside protects primary rat cortical neurons from neurotoxicity induced by amyloid $\beta$-protein via the $\mathrm{PI} 3 \mathrm{~K} / \mathrm{Akt} / \mathrm{Bad} / \mathrm{Bcl}(\mathrm{XL})$-regulated mitochondrial apoptotic pathway. Eur J Pharmacol 672: 45-55, 2011.

33. Sakamaki J, Daitoku H, Ueno K, Hagiwara A, Yamagata K and Fukamizu A: Arginine methylation of BCL-2 antagonist of cell death (BAD) counteracts its phosphorylation and inactivation by Akt. Proc Natl Acad Sci USA 108: 6085-6090, 2011.

34. Zhao A, Zeng Q, Xie X, Zhou J, Yue W, Li Y and Pei X: MicroRNA-125b induces cancer cell apoptosis through suppression of Bcl-2 expression. J Genet Genomics 39: 29-35, 2012. 